\title{
LINKING SMES' CLUSTERS: A VIEW OF THE INFORMATION INFRASTRUCTURE
}

\author{
María Elena Léon, Rodrigo Salamoni, João Amato Neto \\ Escola Politécnica - Departamento de Engenharia de Produção \\ Universidade de São Paulo. \\ BRAZIL \\ melena@usp.br,rsalamoni@yahoo.com,amato@usp.br
}

\begin{abstract}
Rapid advances in scientific and technical knowledge and declining costs of producing, diffusing and processing information are transforming activity world-wide and thereby leading to the emergence of the so-called knowledge based economies. With recent developments in information and communication, technologies are opening up the potential for linking such similar local and regional cluster. The prosperity of local and regional economies is increasingly seen to depend upon groupings or "clusters" of firms, connected through vertical and horizontal relationships. This paper describes the main information technologies that SMES need for achieving competitiveness within productive cooperation networks, for example, the Internet. The research methodology used was case study in SMES' cluster in the São Paulo State.
\end{abstract}

\section{INTRODUCTION}

Information technology has long been recognized as a dynamic facilitator of organizational success and profitability (Porter, 1985). Reduced information technology costs, flexibility and enhanced information technology capabilities have enable information technology to evolve from a reactive organizational tool to a proactive corporate resource (Segars and Grover, 1994). However, much of the literature on information technology is related to large organizations that have the investment capability to build up sophisticated information system. Large firms have the potential to either lock-in or link up electronically with customers, trading partners and suppliers. With the incorporation of smaller firms into information technology networks due to the decrease in information technology hardware and software costs, smaller enterprises are now major users of information technology.

In the manufacturing sector the use of supply chain based networks is already well established. The beneficial use of such networks by small firms can often overcome the competitive advantages that larger firms have through economies of scale (Curran et al., 1993). Effective networking is vital to the success of the small 
firm (Poon et al., 1996) and the use of information and communication technology offers a relatively low cost solution.

\section{THE POTENTIAL FOR BUSINESS GROWTH}

The potential for business growth using information and communication technology has been recently highlighted in a new study by the world Trade organization (1998), which outlines the potential trade gains from the rapidly increasing use of the Internet for commercial purposes and predicts that by the year 2000 the value of electronic commerce will reach US $\$ 300$ billion. However, the extent to which the small firm will benefit from the electronic market place will be influenced by take up rates of information and communication technology. In 1995, the rates of PC use across the European Union declined by firm size, falling to $24 \%$ for businesses employing less that 20 people (EITO, 1995).

According to Connor (1999), over the last four years, this trend has changed and an increasing number of small firms now have PCs with proprietary software with the capability to network electronically but few of them are taking advantage of this opportunity.

\section{THE POTENTIAL FOR NETWORKS OF SMES}

Clearly there is considerable potential for small firms to benefit from these new opportunities but at the present time, there is only limited evidence to show that this potential is being achieved. Information and communication technology has the potential to foster co-operation and co-ordination of transactions between organization and allowing SMES to set up strategic partnerships that have the potential to consolidate their competitive position and enlarge their market share (Porter, 1985).

Much of the direction of existing initiatives to promote the take up of information and communication technology has been driven by the European Union. This has involved a convergence of technological process and infrastructure and the creation of information and communication technology networks across European Union countries. However, this approach has been essentially supply-driven and has been a critical factor in the limited take up of these new technologies by small firms. (Com., 1996).

\section{BENEFITS OF INTERNET USE FOR SMALL BUSINESS}

"Advances in information technology for small firms have moved rapidly over the last decade, particularly in relation to small firm/large firm electronic linkages (Connor, 1999 apud Gales and Blackburn, 1990, Ferguson, 1995) and more recently, with the use of the Internet (Connor, 1999 apud Kaplan et al 1997). The Internet can present opportunities to create and implement new ways of doing business (Nath, 1998). As such, small firms in the service sector can take advantage of this 
technology for relatively low entry and establishment costs (Peterson et al, 1998). Small firms are also able to participate in electronic data interchange (EDI) at lower cost by running EDI messages over the internet without paying network messaging fees" (Corbin, 1996, Tucker, 1997,apud Drennan, 1999).

The ability to compete more effectively with larger organizations by using the Internet is a significant advantage for SMES clusters. The enterprises are more visible to competitors and consumer on the Internet, and smaller firms that set up a Website are able to compete by virtue of its presence (Drennan, 1999 apud Guthrie and Austin, 1996).

\section{FACTORS AFFECTING INTERNET USE}

To investigate factors affecting Internet Use, Drennan (1999) consider past research relating to information technology developments such as electronic data integration. A study undertaken by Iavocou et al (1995) proposes that adoption of international technology may be influenced by at least three factors: organizational readiness, external pressure to adopt and perceived benefits.

Organizational readiness involves the level of financial and technological resources of the firm.

External Pressure relates to government, competitive and customer demands.

Perceived benefits include recognition by the firm of the relative advantage to be gained by the information technology network.

\section{LINKING SMES CLUSTERS: BRAZILIAN CASE}

The successful development of cooperation networks (Clusters) among small and medium size companies depends on a lot of specific conditions: First of all it relies on the existence of appropriate infrastructures. The necessary conditions for the rising of cooperation networks in Latin America countries such as Brazil could be resumed in the next points, based on Goranson (1995):

- Legal Infrastructure: The needs for reforms in Government Policies in Latin American countries;

- Physical Infrastructure: creation of adequate telecommunication and information highways;

- Information Infrastructure: development of reliable and accurate industrial databases.

- Social/Cultural Infrastructure: development of an Entrepreneur Culture in Latin American Small and medium enterprises.

Regarding the information infrastructure, there is no reliable information about the state of industry in most of the Latin American countries.

Our study identify some Industrial cluster in Brazil. First of all, there are three regions, which are specialized in shoe industry. The most important of them is the shoe industry of Franca, a medium size city sited in the north of the State of São Paulo. This region is specialized in men's leather shoes. In that region it is possible to observe the predominance of SMES working together with some large companies 
as Samello, Sandalo and Vulcabrás, traditionally exporting companies (Garcia, 1996 apud IPT, 1998).

There is a strong predominance of SMES in this region (Franca). Among 390 shoemaker companies, 365 are micro or small ones (94\% of all). Other $15(3,8 \%)$ are medium size and only $10(2,5 \%)$ are large companies. In average terms, the companies work with 30 days of lead-time. The most part of the companies has low degree technology, using old equipment in general, and in some special cases of automation, they are rigid type, that is, not flexible production systems are used.

The other region is Birigui, a small town sited in the center of the São Paulo State, specialized in children's shoe production made of synthetic material. The third region is the city of Jau, which produces women's leather shoes. In both cases (Birigui and Jau) a greater presence of SMES can be observed. This fact could represent a great potential to the inter-firm cooperation relationship among those companies.

The other predominant region cluster in São Paulo is the textile and clothing in Americana, a medium size city (sited $100 \mathrm{~km}$ north from São Paulo city). In this region, one can feel the intense impact of the commercial liberalization for the imported articles, mainly those coming from the Asiatic southeast (china specially).

In terms of Internet utilization, it was observed that only $10 \%$ of all the companies utilize this kind of resource, in spite of the existence of three Internet providers in that region. The limitations refer to the lack of new investments in the new telecommunication infoways, which imply more intensive utilization of optical fiber and digital systems replacing the real analogous ones. In the way, the Brazilian public authorities are already announcing investments around US $\$ 90$ billion in the telecommunication system until the year 2002 in order to implement a suitable infrastructure to support the enterprise competitive power under the context of a global economy.

\section{INTERNET ACCESS TECHNOLOGIES}

Nowadays, the establishment of an electronic data network communication as well as the meetings of partners with abilities are important for a SMES cluster to prosper. Therefore, Internet is a powerful developing tool for them, once Internet is a global environment, where enterprises can expose their products, services and change information. In addition, when we focus on SMES, a great advantage raises with the use of Internet: we cannot distinguish small from large companies. The impact and the information format of both size companies are very similar in the net.

Nevertheless, to start using the Internet like the main communication environment, it has to work fast. Internet allows to transmit many types of files: texts, movies, sounds, pictures but depending on the size of the file it could take much time, and companies cannot wait that long.

Based on that, a research on new technologies of Internet access will be presented. 


\subsection{A brief commentary about common phone lines}

Common phone lines have been developed to work with human voice, and thus, they do not work directly with binary data. This system use analog signals.

Therefore, a converter called MODEM (MODulator/DEModulator) is necessary to change binary data (proceeding from computer) in different tones of phone lines and vice-versa.

A common modem achieves $33,600 \mathrm{bps}$. However, phone lines rarely work at this speed because interferences, which cannot be avoided, mixed to analog signals cause errors in data transmission. Therefore, a retransmission is needed and the speed, which was $33,600 \mathrm{bps}$, goes down to $20,000 \mathrm{bps}$.

Today, we can buy $56,000 \mathrm{bps}$ modems, but due to lines interference this speed is rarely achieved. In old times, when just binary files and small texts were transmitted through the net, 33,600bps analog modems were enough.

However, nowadays, an enormous amount of graphs, archives with music and movies are transmitted and this speed becomes insufficient to handle all this potential. A research about the new faster connection technologies to the Internet will be presented.

\subsection{ISDN (Integrated Services Digital Network)}

ISDN uses optic fiber cables to transmit digital signals. The ISDN service suited for residential, and small enterprises use (BRI (Basic Rate Interface) makes use of two $64 \mathrm{Kbps}$ channels, called B channels. The B channels can be combined for a maximum capacity of $128 \mathrm{Kbps}$, roughly four times the capacity of a $33.6 \mathrm{Kbps}$ analog modem. Because ISDN is a digital network, it is more efficient than analog phone lines at carrying packets of data on the Internet. For activities that send small amounts of data frequently, such as Internet gaming, it may seem far more than four times as fast as an analog connection.

You can make voice calls on an ISDN line, and many adapters allow you to use your phones. Each B channel can carry a phone call, so you can access the Internet on one B channel and make or receive a voice call on the other. Some ISDN adapters let you use both B channels to access the Internet and shut down one B channel to let you answer an incoming call.

ISDN also has a third channel, called the D channel, which has a maximum capacity of only $16 \mathrm{Kbps}$. The D channel was designed for signaling (to indicate the line is busy, for instance), and its bandwidth is usually not available to you. However, some phone companies allow you to use the D channel as a continuous connection to the Internet. Because the D channel has low throughput, it is well suited to sending and receiving relatively small amounts of data at regular intervals, like e-mail or stock quotes. The primary advantage of such service is that you can get small amounts of data without placing an ISDN call, which often incurs perminute charges.

The communication system between enterprises presents considerable improvement, when they make use of this technology, because it allows transferring archives fast, doing teleconferences and loading pages full of pictures with a considerable speed. 
According to Russo (1998), one problem of ISDN lines consists of not having a specific standard for ISDN, which can cause incompatibility problems.

Moreover, many countries (for example, the Latin American countries) and still many regions of Brazil do not have this technology. Thus, a company, which has ISDN, will not be able to enjoy its potential during transactions with a country or region that work with the analog system.

Another problem is the distance between the phone company and the users. Digital transmission is only available up to 6000 meters distant. It is valid to emphasize that the ISDN, although extremely recent, seems to become obsolete.

It has already started to work another faster types of Internet connection systems in Brazil.

Two new technologies are competing in this market. Cable providers and access providers, in this order, are installing Cable modem and ADSL in Brazil. They offer the higher speed connections nowadays.

\subsection{Cable modems}

Cable modems are devices used for transferring data through cable TV. This type of cable (coaxial), used to transmitting analog television signals, has a bandwidth bigger than the traditional phone lines ones. This fact is responsible for the high speed it achieves.

A special modem is connected to a TV cable and then, to a PC, speeding up the Internet access. It can operate at $10 \mathrm{Mbps}$, but not always because the data bandwidth on a cable modem network is shared by groups of users. As the number of users online increases, each user's share of bandwidth goes down.

You can realistically expect peak speeds of up to 2 million bits per second, compared with $128 \mathrm{Kbps}$ for ISDN or $28.8 \mathrm{Kbps}$ for a modem.

Until months ago, just the "one way" system was working, which uses cable only for downloads. For uploads they use the phone line.

In the beginning of this year, GloboCabo installed the "two way" system, which uses cable for download and upload.

Besides providing faster access, cable modems keeps the phone line free.

In Brazil, the precariousness and obsolescence of all infrastructure of telecommunication system limit the great potential offered by the Internet. So using cable-modem, companies will not have to wait for investments in telecommunication, and they will eliminate costs with phone calls. Moreover, a great part of the infrastructure for the cable modem use is already installed: it is the same of the cable TV.

Working against cable modem are: a possible lost of speed access with the growth of users number; the necessity of installing this system an entire all a neighborhood (you can not use that if your neighborhood do not have the system) and the price: the cable modems are relatively expensive compared with ISDN devices. If you add to the installation fee, monthly charges and cable access it begins to look pretty expensive. However, specialists say that this technology will be viable to SMES in roughly 18 months. 


\subsection{ADSL (Asymmetric Digital Subscriber Line)}

ADSL is one of the systems DSL existent (also called XDSL). ADSL is a new digital networking technology that runs on existing copper telephone wires. A typical performance for these devices is around $1.5 \mathrm{Mbps}$ for downloads and $64 \mathrm{Kbps}$ for uploads, and that is why it is being called Asymmetric.

An ADSL line requires two modems, one on the user side, and one on the telephone companies. ADSL supplies three separate frequency channels over the same line. One channel carries telephone conversations, and another carries a 16 to $640 \mathrm{Kbps}$ data signal upstream from a user to the Internet. The third channel is a high-speed downstream connection running anywhere from $\mathrm{T} 1(1.544 \mathrm{Mbps})$ to 9Mbps.

Despite the bandwidth advantages, ADSL faces some technical constraints. Range is pretty limited. In fact, the higher the data rate, the closer the user and central office must be. In addition, prices are still high too.

\subsection{Access Technologies in Brazil}

Just last year the increase of competition among Telephone Company's made the launching of products like cable modems (@jato of TVA and Virtua of GloboCabo), ADSL and ISDN possible. On one hand, cable modem offers a solution to free the telephone line and on other hand, ADSL (called Speedy in São Paulo and traded by Telefônica) and ISDN (traded by Telefônica and Telemar) are technologies that search the best exploitation on the existing telephonic plant. It is excellent for the telephone companies, which can supply an additional line without extending the capacity of the telephonic central. The main difference between the ISDN and the ADSL is that the ISDN is charged by time of use, while the monthly fee of the ADSL is always the same one, independently from the use.

According to a tableau of prices in the site http://www.uol.com.br/speeduol/ (12/03/2000), ISDN presents lower installation costs compared with ADSL and cable modem, but it is necessary to be connected throw a phone line to work, which represents an additional cost.

Therefore, focusing on SMES that do not belong to any network, an appropriate choice for them, among these access technologies, would be ISDN, because considering its reasonable costs, it allows working with four times the capacity of a $33.6 \mathrm{Kbps}$ analog modem, which is sufficient to have agility in the net nowadays. But if the enterprise needs to stay connected for several hours a day, ISDN would imply in high phone connection costs, which could make this alternative not interesting anymore. In this case, an economic viability study should be elaborated.

In networks of SMES, the use of ADSL or cable modems is more recommended since they are faster than ISDN and their high costs could be shared among the enterprises of the network. 


\section{CONCLUSIONS}

The potential for business growth using information and communication technology is great. Our research has shown a marked increase in PC usage among small firms and although many small firms have the capability to trade electronically, they have as yet failed to capitalize on the business potential because they do not fully understand how these new approaches can benefit their business.

Small size enterprises gain more experience with computers. They may become more self-confident and knowledgeable in approaching the use of new information technology developments.

\section{ACKNOWLEDGEMENTS}

This work was supported by a grant from FAPESP, process 98-15576-3.

\section{REFERENCES}

1. Commission of the European Communities. Living and working in the information society: people first, green paper. COM. Brussels, 1996.

2. Connor J.,Woodburn B. Information and communication technology and small Firms: the potential for Business Growth. International Conference Small Business. Naples- Italy. June-1999. Pag109.

3. Curran, J. jarvis, R. Blackburrn, R. ${ }^{a}$ and Blacks, S. Networks and small firms: constructs, Methodological strategies and Some Findings, international small business journal, Januarymarch 11 (2) pp 13-26, 1993.

4. Drennan Judy, Kennedy J. Internet Use factors for Small Business. Working Paper ICBS . Naples Italy June, 1999.

5. EITO - European Information Technology Observation. Germany, 1995.

6. Iacovou, charalambos 1., Izak Benbasat, Albert S. Dexter. Electronic Data Interchange and small Organizations, , Adoption and impact of technology. MIS Quarterly. 1995.

7. Nath RM, Hjelm K; Sakaguchi,t and Schultz M. Electronic commerce and internet : issues, problems and perspectives. International Journal of information Management, vol 18, No. 2, pp 91-101, 1998.

8. Poon, S. and Swatman, P. Internet-enabled strategies advantage: a new perspective on small business inter-organizational relationships. Proceedings of the $29^{\text {th }}$ Hawaii Conference in systems Science, Hawaii, 1996.

9. Porter, Michael. Competitive Advantage: Creating and sustaining superior performance. Free Press, New York, 1985.

10. Russo N, Pikman M,.Amato Neto J. Redes de Empresas e o Desenvolvimento da Tecnologia da Informação. In Annals of Encontro Nacional de Engenharia de Produção, Niterói-RJ, oct/1998.

11. Segars $\mathrm{H}$ and Grover V. Strategic group Analysis: A Methodological approach for exploring the industry level of information technology, Omega, International Journal of Management Science.Vol. 22 No. 1, pp13-34, 1994. 